\title{
Analysis of caesarean delivery using Robson ten group classification system at a tertiary care teaching institute in Kerala, India
}

\author{
Heera Shenoy T. ${ }^{1}$, Sheela T. Shenoy ${ }^{2}$, Anaswara T. ${ }^{3}$, Remash K. ${ }^{4 *}$
}

\begin{abstract}
${ }^{1}$ Department of Obstetrics and Gynaecology, Travancore Medical College, Kollam, Kerala, India ${ }^{2}$ Department of Obstetrics and Gynaecology, Govt. Medical College, Trivandrum, Kerala, India ${ }^{3}$ Student, Department of Obstetrics and Gynaecology, Travancore Medical College, Kollam, Kerala, India ${ }^{4}$ Department of Cardiology, Travancore Medical College, Kollam, Kerala, India
\end{abstract}

Received: 28 February 2019

Accepted: 02 April 2019

\section{*Correspondence:}

Dr. Remash K,

E-mail: heerarprabhu@gmail.com

Copyright: () the author(s), publisher and licensee Medip Academy. This is an open-access article distributed under the terms of the Creative Commons Attribution Non-Commercial License, which permits unrestricted non-commercial use, distribution, and reproduction in any medium, provided the original work is properly cited.

\section{ABSTRACT}

Background: Globally, the caesarean delivery rate is rising continuously, making caesarean one of the most common surgical procedures. The Robson classification, appreciated by WHO in 2014 and FIGO in 2016 is widely accepted, risk-based, ten-group classification system (TGCS) developed specifically to assess caesarean section rates. The aim of this study was to know the rate of Caesarean section in present hospital, to analyse the Caesarean sections based on Robson's classification and to determine the contribution and significance of each group on the overall number of Caesarean sections.

Methods: All women, who gave birth by Caesarean deliveries done over a period of 1 year (January 2018-December 2018) in Travancore Medical College Hospital in South Kerala India.

Results: Group 5 (previous LSCS, single, cephalic >37 weeks) made the greatest contribution to the Caesarean section rate $(27.24 \%)$. The second highest contributor was Group 2 (Nulliparous, singleton, cephalic, >37 weeks induced labour or caesarean section before labour followed by Group 10 (all single cephalic <36 weeks including previous CS) $18.78 \%$.

Conclusions: Limiting the CS rate in low-risk pregnancies is key to lowering the trend of increased CS. If TGCS is used uniformly, CS rates can be compared over time and between units, both nationally and internationally.

Keywords: Caesarean delivery, Contribution, Indication, Induction of labour, Previous caesarean, Robson TGCS

\section{INTRODUCTION}

Globally, the caesarean delivery rate is rising continuously, making caesarean one of the most common surgical procedures. ${ }^{1}$ One in five pregnant women undergoes caesarean delivery. ${ }^{1}$ Caesarean rates vary between countries and even between hospitals within the same country. ${ }^{2}$ The World Health Organization (WHO) stated, there is no justification for any region to have a Caesarean section rate higher than $10-15 \% .^{3}$ The rate of Caesarean Sections below 5\% seems to be associated with gaps in obstetric care leading to poor health outcomes for mothers and child, whereas rates over $15 \%$ don't seem to improve either maternal or infant health. ${ }^{4}$ Caesarean rates continue to increase worldwide and have become a major public health concern. Proportion of CS to the total births is considered as one of the important indicators of emergency obstetric care (World Health Organization, 2009). According to the latest data from the National Family Health Survey 2015-16 (NFHS-4), caesareans have doubled over the last decade across India. There is $16.7 \%$ rise in Caesarean section cases annually in India. The proportion of women who have undergone caesarean deliveries is the highest in Kerala (31.8 per cent) followed by Andhra Pradesh (29.3 per cent). ${ }^{5}$ 
Caesarean section rate (CSR) is one of the most frequently used indicators of healthcare quality at the national and international levels for clinical governance. ${ }^{6}$ Besides, unnecessary caesareans generate higher expenditure at individual and national levels and also have the potential to divert human and financial resources from higher priority intervention). In India the rate of CS is substantially higher in private health care institutions compared to public health care institution. When controlled for demographic variables, the odds for Caesarean Section were about 1.7 times more likely to occur in private health institutions in Kerala. ${ }^{5}$ A combination of demographic, socio-economic and institutional factors determines the rate of caesarean section delivery in any region. Recent temporal trends in maternal characteristics that have contributed to increase in this rate include increasing maternal age and higher rates of hypertension, diabetes, obesity, and multiple gestations. Caesarean section is associated with both immediate and later risk of maternal and neonatal complications.

The Robson classification, appreciated by WHO in 2014 and FIGO in 2016 is widely accepted, risk-based, tengroup classification system developed specifically to assess caesarean section rates. ${ }^{6}$

It allows comparison of clinically meaningful maternity population subgroups and the associated Caesarean section rates across institutions, countries, development groups, and time. This classification system categorizes women into 10 mutually exclusive groups, considering the following criteria: obstetric history (parity and previous Caesarean section), onset of labour (spontaneous, induced, or Caesarean section before onset of labour), foetal presentation or lie (cephalic, breech, or transverse), number of foetuses, and gestational age (preterm or term). ${ }^{7}$

The number of caesareans and total deliveries, relative group size (number of deliveries in the group/total number of deliveries), caesarean rate, and contribution of the total caesarean rate size (number of caesarean deliveries in the group/total number of caesarean deliveries). The size and CS rate of a group must be considered together-a low caesarean rate in a large group contributes more to the total caesarean rate than a high caesarean rate in a very small group. This not only permits examination of group-specific rates to determine their appropriateness, but also demonstrates how the overall rate of CS is affected by both the magnitude of the group-specific rates and the relative size of each group, thus identifying groups that make the greatest contribution to the overall rate of CS. The aim of this study was to know the rate of Caesarean section in present hospital, to analyse the Caesarean sections based on Robson's classification and to determine the contribution and significance of each group on the overall number of Caesarean sections.

\section{METHODS}

\section{Inclusion criteria}

All women, who gave birth in this tertiary care centre during the specified period, were eligible for inclusion and authors collected the details of all Caesarean deliveries done over a period of 1 year (January 2018December 2018) in the Department of Obstetrics and Gynaecology in Travancore Medical College Hospital in South Kerala.

\section{Exclusion criteria}

- Authors excluded cases of hysterotomies and rupture uterus - both scarred and unscarred.

- The medical records that were incorrectly or incompletely filled.

Information was retrieved from the case files of all patients who underwent Caesarean section in 2018 were obtained from the medical record library. All the data related to maternal age, parity, domicile, occupation, socio-demographic strata and reproductive career, medical co-morbidities, spontaneous/induced labour and indication of Caesarean section were noted. oFetal details as birth weight, alive/dead were looked into. Maternal complications and length of hospital stay in days were entered in an excel sheet.

Women were classified in 10 groups according to Robson's classification (Table 1), using above information. For each group, authors calculated its relative size and its contribution to the overall Caesarean rate and also analysed the indications of caesarean delivery in the groups that ranked the greatest in this scoring system. Furthermore, the use of the TGCS is particularly significant, considering that Kerala is the only major state in India, which exceeds the WHO, specified fifteen percent with respect to the rural csection and the highest percentage of c-section with 25.74 percent of all births. ${ }^{8}$ The primary outcome was the contribution of each group to the overall caesarean section rate. The secondary outcome was to identify the main contributors to the caesarean section rates in this centre.

\section{Robsons groups classification type}

- Group 1- Nulliparous, singleton, cephalic, >37 weeks in spontaneous labour

- Group 2 -Nulliparous, singleton, cephalic, >37 weeks induced labour (2A) or Caesarean section before labour (2B)

- Group 3- Multiparous (excluding previous Caesarean section), singleton, cephalic, >37 weeks in spontaneous labour 
- Group 4 -Multiparous without previous uterine scar, singleton, cephalic, >37 weeks induced labour (4A) or Caesarean section before delivery (4B)

- Group 5- Previous Caesarean section, singleton, cephalic, $>37$ weeks

- Group 6 - All nulliparous with a single breech

- Group 7 - All multiparous with a single breech (including previous Caesarean section)

- Group 8 - All multiple pregnancies (including previous Caesarean section)

- Group 9 - All women with a single pregnancy transverse or oblique lie (including previous caesarean section)

- Group 10 - All singleton, cephalic, < 37 weeks (including previous caesareans).

\section{RESULTS}

Total 655 deliveries were conducted during the study period in this institute including 378 Caesarean sections.

Analysis based on Robson's 10 group classification showed that Group 5 (previous LSCS, single, cephalic $>37$ weeks) made the greatest contribution to the Caesarean section rate $(27.24 \%)$.

The second highest contributor was Group 2 (Nulliparous, singleton, cephalic, >37 weeks induced labour or Caesarean section before labour followed by Group 10 (all single cephalic <36 weeks including previous CS) $18.78 \%$ (Figure 1).

Table 1: Distribution of caesarean delivery using Robson score in our teaching hospital.

\begin{tabular}{|llllll|}
$\begin{array}{l}\text { Robson } \\
\text { TGCS }\end{array}$ & $\begin{array}{l}\text { Total number of } \\
\text { participants in the group }\end{array}$ & $\begin{array}{l}\text { Number of } \\
\text { caesarean } \\
\text { deliveries }\end{array}$ & $\begin{array}{l}\text { Relative sive of the } \\
\text { group (\%) }\end{array}$ & $\begin{array}{l}\text { Caesarean } \\
\text { rate in each } \\
\text { group (\%) }\end{array}$ & $\begin{array}{l}\text { Contribution } \\
\text { made by each group } \\
\text { to overall CS (\%) }\end{array}$ \\
\hline 1 & 123 & 59 & 18.83 & 47.9 & 15.60 \\
\hline 2 & 175 & 92 & 26.79 & 52.57 & 24.33 \\
\hline 3 & 79 & 01 & 12.09 & 1.2 & 0.26 \\
\hline 4 & 49 & 10 & 07.50 & 20.4 & 2.64 \\
\hline 5 & 104 & 104 & 15.92 & 100 & 27.24 \\
\hline 6 & 15 & 14 & 2.29 & 100 & 3.70 \\
\hline 8 & 05 & 05 & 0.76 & 88.88 & 4.32 \\
\hline 9 & 18 & 16 & 2.75 & 100 & 1.85 \\
\hline 10 & 78 & 07 & 1.13 & 91 & 18.78 \\
\hline
\end{tabular}

A total of 653 deliveries occurred during the study period out of which 378 required caesarean section. Table 3 describes the various groups of modified Robson's ten group classification system. It also describes the relative size of each group in terms of number of deliveries and also shows the absolute and relative contribution of each group of Robson's classification to the overall CS rates. The overall rate of surgical delivery in the present study was Group 1 and 2 (nulliparous, singleton, cephalic, $\geq 37$ weeks' gestation, in spontaneous labour/ induced labour or caesarean section before labour) comprised almost half $(45.62 \%)$ of the study population. Women with previous CS, singleton term pregnancy (Group 5) comprised nearly $16 \%$ of the total population. Group 10 comprised of $64(11.94 \%)$ women with preterm singleton pregnancy with cephalic presentation.

Group 4 included $7.50 \%$ women who were multiparous without a previous uterine scar, with singleton, cephalic term pregnancy, and induced or caesarean section before labour.

Amongst 20 (3.05\%) women with breech presentation, 15 (2.29\%) were nulliparous (group 6) and the remaining 5
$(0.76 \%)$ were multiparous (group 7). Eighteen women $(2.75 \%)$ had multiple pregnancies (Group 8) and seven women had abnormal lies (Group 9).

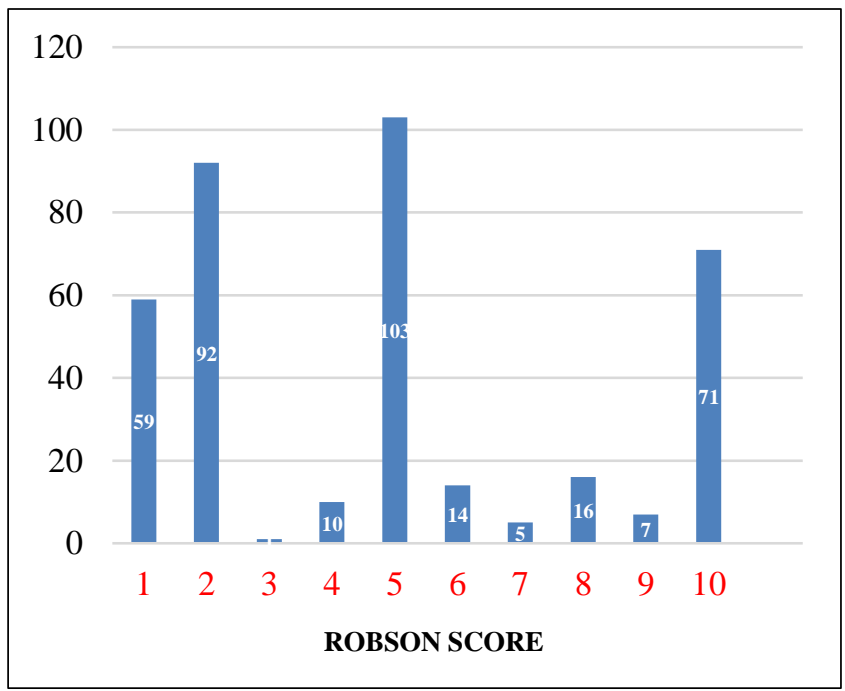

Figure 1: Distribution of Caesarean section based on Robson's TGCS in our teaching hospital. 
All the deliveries in group 5 (previous caesarean section), group 7 (multiparous, single breech) and group 9 (transverse or oblique lie) were surgical deliveries. Relatively high surgical delivery rates were seen in group 10- (91\%), group 6 -nulliparous, single breech $(99.33 \%)$, group 8 - multiple pregnancies $(88 \%)$, group 2 -full -term, nulliparous, singleton, cephalic $(52.57 \%)$, the other groups in descending order of surgical deliveries were group $1(48 \%)$ and group $4(20.4 \%)$. Least surgical delivery rate was observed in group $3(1.2 \%)$ multiparous women without previous caesarean section, singleton, cephalic, $\geq 37$ weeks' gestation and in spontaneous labour.

Table 1 describes the absolute and relative contribution of each group of Robson's classification to the overall CS rates. The overall rate of surgical delivery in the present study was $57.88 \%$. Group 5, group 2, group 10 and group 1 were the leading contributors to the overall rate of surgical delivery in relation to total number of deliveries. Rest all groups contributed to around $2 \%$ or less of surgical deliveries in relation to total deliveries.

Table 2: Sociodemographic variables and caesarean delivery.

\begin{tabular}{|lll|}
\hline Characteristic & Number of caesareans & $\%$ \\
\hline Maternal age (years) & 10 & $(2.64)$ \\
\hline$<20$ & 78 & $(20.63)$ \\
\hline $20-24$ & 177 & $(46.82)$ \\
\hline $25-29$ & 78 & $(20.63)$ \\
\hline $30-34$ & 31 & $(8.20)$ \\
\hline$>35$ & & \\
\hline Employed during pregnancy & 107 & $(28.3)$ \\
\hline Yes & 271 & $(71.7)$ \\
\hline No & & \\
\hline Domicile & 199 & $(52.6)$ \\
\hline Urban & 179 & \\
\hline Rural & & $(94.7)$ \\
\hline Status of Subject & 358 & $(5.3)$ \\
\hline Booked & 20 & $(23.8)$ \\
\hline Referred & & $(39.4)$ \\
\hline Socioeconomic class & 90 & $(36.8)$ \\
\hline Lower & 149 & \\
\hline Middle & 139 & \\
\hline Upper & & \\
\hline
\end{tabular}

Table 3: Reproductive career and caesarean delivery.

\begin{tabular}{|lll|}
\hline Characteristic & Caesareans & $\%$ \\
\hline Primigravida & 200 & $(52.91)$ \\
\hline Multigravida & 178 & $(47.08)$ \\
\hline Infertility treated & & $(7.2)$ \\
\hline Yes & 27 & $(92.8)$ \\
\hline No & 351 & $(79.6)$ \\
\hline H/O Abortion & & $(20.4)$ \\
\hline No & 301 & \\
\hline Yes & 77 & $(2.2)$ \\
\hline Ectopic pregnancy & 08 & $(6.09)$ \\
\hline Yes & & $(41)$ \\
\hline Previous Obstetric H/O & 23 & $(52.91)$ \\
\hline FTND & 155 & \\
\hline Previous cesarean & 200 & $(92.25)$ \\
\hline Not applicable & & $(7.09)$ \\
\hline Previous cesarean & 143 & $(0.64)$ \\
\hline One & 11 & \\
\hline Two & 01 & \\
\hline Three & & \\
\hline
\end{tabular}


Majority of mothers were in 25-29 year age group (46.82\%) and equal $20.63 \%$ ) $\%$ of mothers in 20-24 and $30-34$ year. $28 \%$ were employed during this pregnancy. Urban settled women comprised $52.6 \%$ and there were $5.3 \%$ obstetric referrals in our research study. $53 \%$ of first time mothers and $6.2 \%$ of multipara underwent primary caesarean. $7.2 \%$ had received treatment for infertility. $20.4 \%$ had history of pregnancy loss $2.2 \%$ had previous tubal pregnancy.
$41 \%$ of our women had previous caesarean delivery (obstetric historical risk) and 11 of them had previous 2 caesareans and there was a mother with previous three caesarean deliveries.

The most common indication was previous caesarean delivery followed by failed induction and nonprogression of labour.

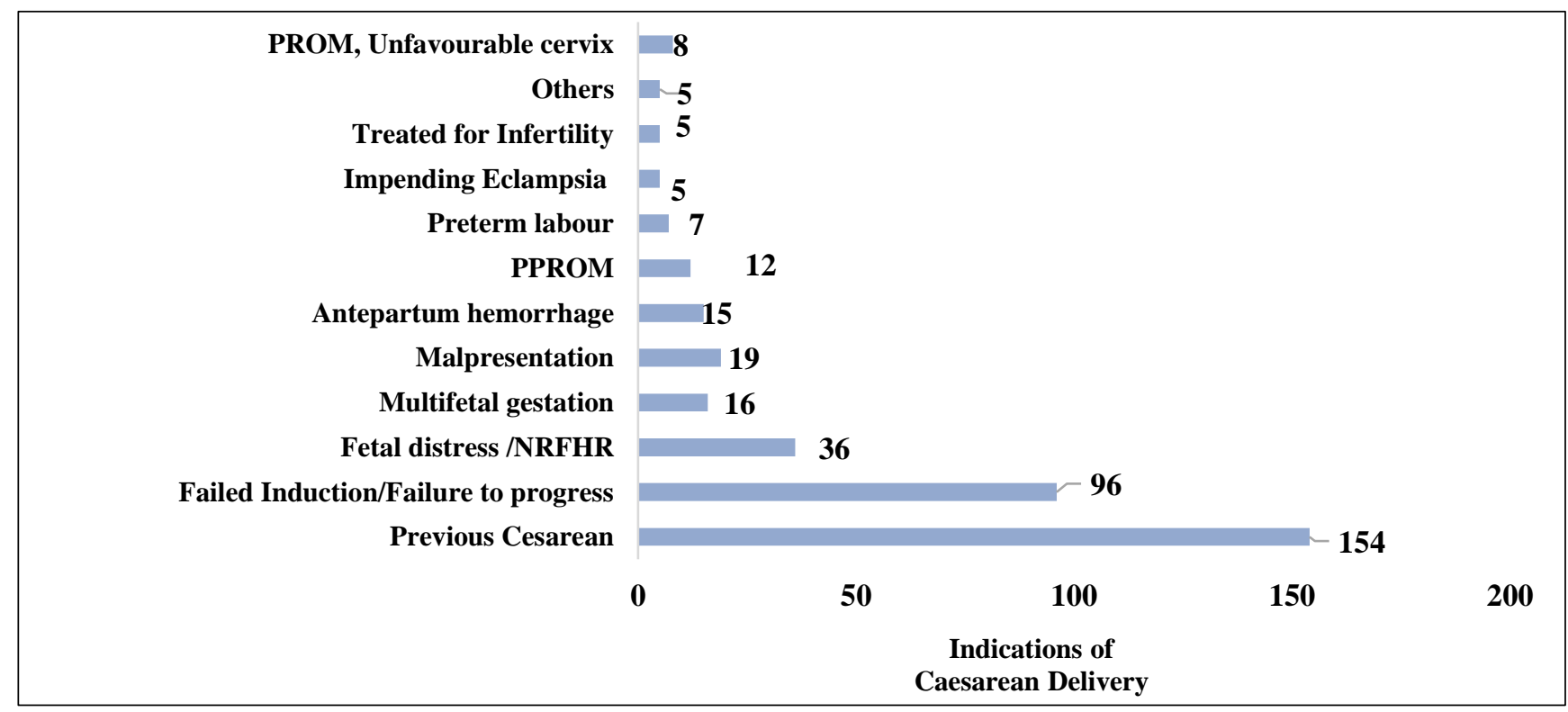

Figure 2: Indications of Caesarean delivery in our teaching hospital.

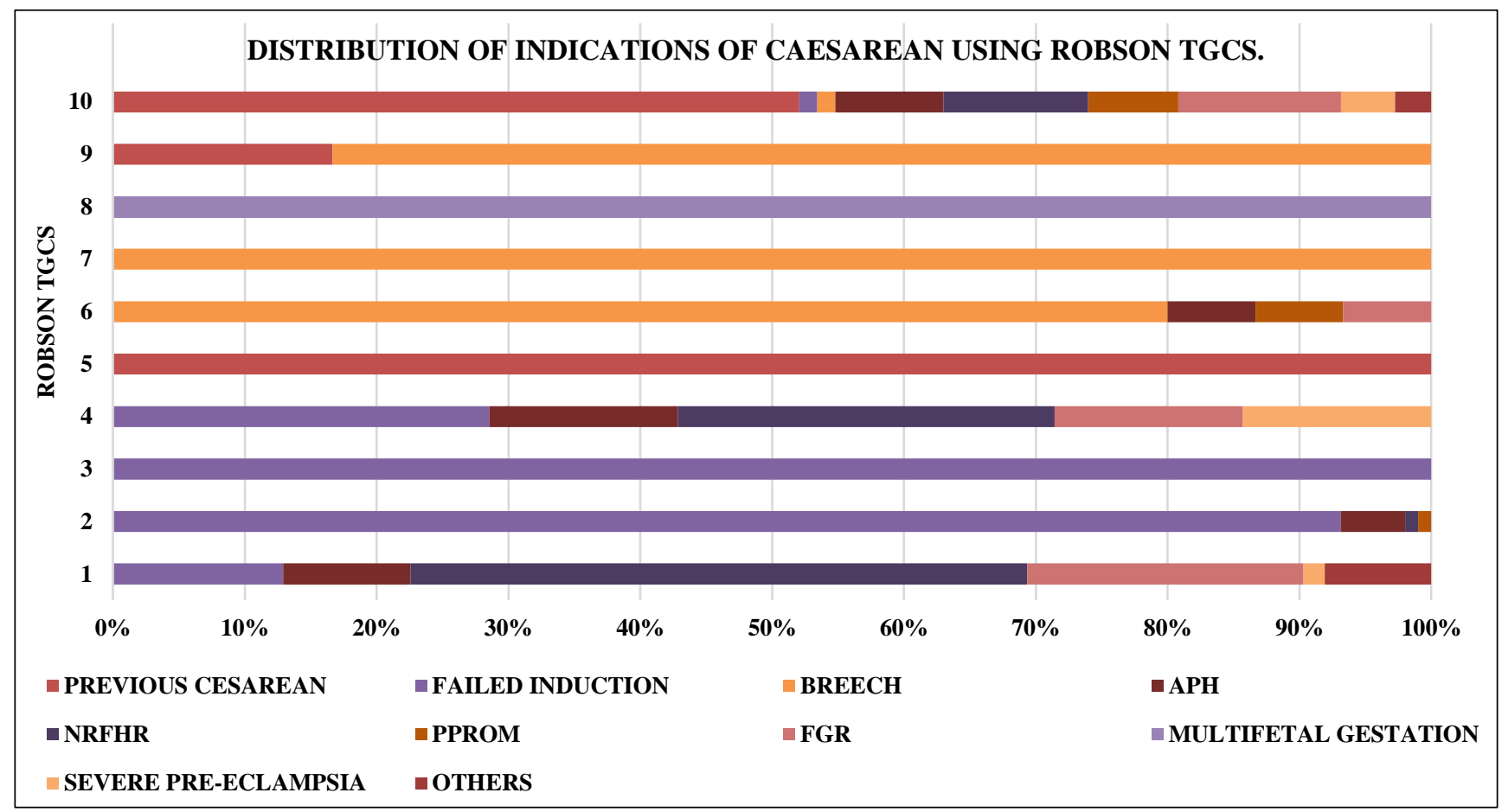

Figure 3: Indications for CS within the 10 groups in our teaching hospital. 
A total of 653 deliveries occurred during the study period out of which 378 required caesarean section. Table 3 describes the various groups of modified Robson's ten group classification system. It also describes the relative size of each group in terms of number of deliveries and also shows the absolute and relative contribution of each group of Robson's classification to the overall CS rates. The overall rate of surgical delivery in the present study was Group 1 and 2 (nulliparous, singleton, cephalic, $\geq 37$ weeks' gestation, in spontaneous labour/ induced labour or caesarean section before labour) comprised almost half $(45.62 \%)$ of the study population. Women with previous CS, singleton term pregnancy (Group 5) comprised nearly $16 \%$ of the total population. Group 10 comprised of $64(11.94 \%)$ women with preterm singleton pregnancy with cephalic presentation. Group 4 included $7.50 \%$ women who were multiparous without a previous uterine scar, with singleton, cephalic term pregnancy, and induced or caesarean section before labour.

Amongst 20 (3.05\%) women with breech presentation, 15 $(2.29 \%)$ were nulliparous (Group 6) and the remaining 5 $(0.76 \%)$ were multiparous (group 7$)$. Eighteen women $(2.75 \%)$ had multiple pregnancies (Group 8) and seven women had abnormal lies (Group 9).

All the deliveries in group 5 (previous caesarean section), group 7 (multiparous, single breech) and group 9 (transverse or oblique lie) were surgical deliveries. Relatively high surgical delivery rates were seen in group 10- (91\%), group 6 -nulliparous, single breech $(99.33 \%)$, group 8- multiple pregnancies $(88 \%)$, group 2 -full -term, nulliparous, singleton, cephalic $(52.57 \%)$, the other groups in descending order of surgical deliveries were group $1(48 \%)$ and group $4(20.4 \%)$. Least surgical delivery rate was observed in group $3(1.2 \%)$ multiparous women without previous caesarean section, singleton, cephalic, $\geq 37$ weeks' gestation and in spontaneous labour.

Table 1 describes the absolute and relative contribution of each group of Robson's classification to the overall CS rates. The overall rate of surgical delivery in the present study was $57.88 \%$.

Group 5, group 2, group 10 and group 1 were the leading contributors to the overall rate of surgical delivery in relation to total number of deliveries. Rest all groups contributed to around $2 \%$ or less of surgical deliveries in relation to total deliveries.

\section{DISCUSSION}

Over the years there is a steady increase in trends of surgical delivery in India as well as across the globe. As per the latest data (National Family Health Survey 201516 (NFHS-4), the caesarean rates at population level in India seem to be $17.2 \%$ Kerala State with rapid demographic transition shows high incidence of caesarean childbirth in comparison to other states ${ }^{5}$.
Surgical delivery being associated with increased morbidity and mortality of the mother and baby, there is a need to check this epidemic of surgical delivery.

However earlier no standard classification system was available to identify the characteristics of women likely to undergo surgical delivery and thereby prevent it. Robson Ten Group Classification System for classifying the women undergoing $\mathrm{CS}$ is well accepted internationally and is used for comparison purpose. Standardisation and classification of caesarean deliveries was done for the first time in our department according to the Robson's criteria.

This was an attempt to see which clinically relevant groups contributed most to the caesarean deliveries. As we observed in present study, the rate of caesarean section in our hospital $(57.88 \%)$ is similar to Kant A et al $(53.86 \%)$ quite higher than what has been considered by WHO (15\%) which is higher than in Jogia PD et al $(28 \%)^{9,10}$

In order to interpret the TGCS, Robson suggested following guidelines based on his research and experience. These guidelines are quoted below in quotation mark ("-"). The results of the present study are discussed in this context.

\section{Groups 1 and 2}

"Groups 1 and 2 usually account for $35-40 \%$ of all deliveries; Group 1 should be larger than Group 2 and a CS rate for Group 1 less than 10\% is desirable".

Group 1 and group 2 included a total of $49.53 \%$ women in the present study. Group 2 was larger than group 1 and the CS rate for group 1 was $15.60 \%$. Several studies have proved that it is the groups 1 and 2 that contributed most to the overall CS rates.

It has been proved that $98 \%$ variation in institutional CS rates can be attributed to group 1 and 2 only. The contribution of group 1 and 2 to overall CS rate in the present study was $39.9 \%$ which was in agreement with the findings of Pereira MN et al ${ }^{11}$ and $49.53 \%$ in Jogia PD et al. ${ }^{10}$

\section{Groups 3 and 4}

"Groups 3 and 4 usually account for $30-40 \%$ of women; Group 3 should be larger than Group 4. The CS rate for Group 3 should be $2.5-3 \%$. The CS rate in Group 4 should be below $20 \%$."

Group 3 and group 4 included a total of $19.59 \%$ women in the present study. Group 3 was 1.4 times larger than group 4. The CS rates in group 3 and 4 were just $1.2 \%$ and $20.4 \%$ respectively. 
The CS rate in group 3 is small and is used as a quality check for data collection. If it is more than $3 \%$ probability of inaccurate data increases.

\section{Group 5}

"Group 5 should comprise no more than $10 \%$ of women. With good perinatal outcomes, a CS rate of $50-60 \%$ in Group 5 is excellent”.

Group 5 had proportionately more women with caesarean delivery (27.24\%) which exceeded the suggested limit. All the women in group 5 were delivered by CS. This finding is in agreement with studies done by Kansara Vijay ${ }^{12}$ et al $(98.3 \%$,), Dhodapkar SB et al $(89.6 \%)$ and Shirsath A et al $(87.2 \%)$ where CS rates in group 5 were alarmingly high. ${ }^{12-14}$

"Groups 1, 2, and 5 usually account for two-thirds of all caesarean deliveries."

In the present study group 1, 2 and 5 were responsible for $67.17 \%$ of all the caesarean deliveries which is perfect.

\section{Group 6 and 7}

"Groups 6 and 7 should include 3-4\% of all women, and Group 6 is usually twice the size of Group 7"

The present study has $4.69 \%$ women in group 6 and group 7 together. Group 6 was 3 times the size of group 7.

\section{Group 8 and 9}

"Group 8 should include $1.5-2 \%$ of women. Group 9 should comprise $0.2-0.6 \%$ of women with a CS rate of $100 \%$."

In the present study group 8 had $2.75 \%$ of the study population as there were referred women with multifetal gestation (both twins and triplets) for preterm care and conceived following IVF treatment. All seven with abnormal lie (group 9) were delivered via caesarean.

\section{Group 10}

"Group 10 includes approximately 5\% of women. If the CS rate in Group 10 is $15-16 \%$, it suggests a high proportion of women with spontaneous onset of preterm labour."

The size of group 10 in the present study was $11.94 \%$, which is twice the recommended similar to $9.8 \%$ nearly two times the recommendation. ${ }^{11}$ The CS rate in group 10 was $18.78 \%$, amongst which $72 \%$ were taken for CS before labour, $24 \%$ were in women with spontaneous labour and only $4 \%$ were induced. Premature caesarean indications should be carefully addressed.
"The total number of caesareans and deliveries should be the sum of the number of each event in Robson groups 1 to 10 combined." The results of the present study are in agreement with this observation.

The proportion of women in certain group varied slightly from that suggested by Robson due to relatively small sample size of the study. Dhodapkar SB ${ }^{13}$ et al also had slightly different proportions in some of the groups due to similar reasons. The overall CS rates in the present study was $57.88 \%$ which is higher than that recommended by WHO $15 \%$. However, the rate suggested by WHO was for all deliveries across all institutions. This being a referral centre along with a tertiary care centre, the characteristics of women admitted are different which justifies the higher rate for surgical deliveries in the present study.

This is also the reason for deviation from the suggested rates of CS for different groups by Robson with particular reference to group 5 and group 10 in the present study. Higher overall rates for surgical deliveries ranging from 30 to $40 \%$ were also observed by other studies in India as well as abroad. ${ }^{15-17}$

The present study highlights that group 5 i.e. women with previous CS, contributed maximum $(27.24 \%)$ to the overall surgical deliveries. This finding is consistent with the studies of Dhodapkar SB et al (40\%), Wanjari SA et al $(32.8 \%)$, Shirsath A et al $(54.5 \%)$ and Kansara V et al (46.1\%). ${ }^{12-14,18}$ The only option available to decrease the CS rate in group 5 is trial of labour after caesarean section (TOLAC). In this era of consumer litigations and where both obstetrician and relatives of parturient do not want any added risk, trial of labour after caesarean section is not easily tried unless there is a strong motivation for the expecting mother. Here the key is to reduce the overall size of group 5 by reducing the primary CS rates.

In the present study group 2 was the second largest (26.79\%) contributor of surgical delivery and along with Group 1and 5, was accountable for nearly $60 \%$ of total CS. This finding is in agreement with that of Samba A et al, where groups 2, 4 and 5 contributed nearly half $(47.5 \%)$ of the overall caesarean section rate. ${ }^{19,20}$ In most high-income settings, groups 5,2 and 1 are the major contributors to overall CS rate unlike the studies from low-income settings. ${ }^{21}$ The similarities between highincome settings and our study may be related to fertility trends and, therefore, stronger presentation of groups 1 and 2 in high-income settings, in contrast with stronger presentation of multiparous women (Group 3) in lowresource setting with high fertility rates. Induction of labour (Group 2) is more frequently practised in highincome settings ranging from $8.3 \%$ in Latvia to $33 \%$ in Wallonia (Belgium) compared with $4.4 \%$ in Africa. ${ }^{22,23}$ Risk selection in antenatal care is better developed, which leads to more frequently indicating induction of labour. 
ACOG recently recommended clinical guidelines to restrict the number of cesarean deliveries which are nonmedically indicated and induction of labour before 39 weeks of gestation.

Repeat caesarean delivery accounts for more than one third of all caesarean deliveries in the United States and is one of the leading indicators for caesarean birth. Vogel et al analysed the contributions of specific groups through Robson's 10 group classification system in two WHO multi-country surveys concluded the proportion of women with previous caesarean section has increased along with the caesarean section rate in these women as we see in present study. ${ }^{24}$ Induction of labour and prelabour caesarean in both first time mothers and multiparous have contributed to the current scenario. ${ }^{25}$ Hence, the need of the hour is to limit the induction of labour which has to be evidence based and decided after critical evaluation of the indication of primary caesarean delivery which will decrease primary section rates (Group $1 \& 2$ ) and eventually previous caesarean section rates (Group 5). Our hospital is a tertiary care centre where preterm previous caesareans (obstetric historical risk), women with medical comorbidities, in labour and foetal reasons are referred for expert in- utero obstetric emergency care. There is an increase in trend of caesarean section on maternal request (pre-labour caesarean). Moreover, research also suggests that induction of labour in nulliparous women have increased the CS rates and women with induced labour had higher probability of surgical delivery as compared to women with spontaneous labour. Therefore, induction of labour protocols needs to strictly adhered in order to reduce the burden of unnecessary surgical interventions. ${ }^{26}$ In addition, encouraging vaginal birth after CS (VBAC) and deconstructing the stigma of "once a caesarean, always a caesarean has to be emphasised. Since, TGCS is not an audit of the appropriateness of indications for CS, a continuous audit of indications for CS should be designed to achieve an optimum level of appropriate CS rates.

In study by Dhodapkar SB et al, all the women of group 6 and 7 were delivered by CS.

Samba A et al, reported $93.9 \%$ CS rates for all nulliparous breech presentations similar to $93.3 \%$ in our research study.

Teaching of skills for ECV and assisted breech delivery and their reinforcement along with counselling the parents will help to decrease the need for primary caesarean in women with breech presentation.

\section{CONCLUSION}

Induction of labour and pre- labour caesarean in both first time mothers and multiparous have contributed to the current scenario. Induction of labour protocols needs to strictly adhere in order to reduce the burden of unnecessary surgical interventions. In addition, encouraging vaginal birth after CS (VBAC) and deconstructing the stigma of "once a caesarean, always a caesarean has to be emphasised. By avoiding unnecessary primary caesarean deliveries, authors can lower the caesarean section rates. If TGCS is used uniformly, CS rates can be compared over time and between units, both nationally and internationally. To monitor the CS rates and take appropriate actions it is recommended that Robson's TGCS be used continuously in all health institutions.

\section{ACKNOWLEDGMENTS}

Authors would like to thank the Department of Obstetrics and Gynaecology, Travancore Medical College and medical records library staff for their cooperation and support and all the patients without whom this study might not have been materialized.

\section{Funding: No funding sources}

Conflict of interest: None declared

Ethical approval: The study was approved by the Institutional Ethics Committee

\section{REFERENCES}

1. Betrán AP, Ye J, Moller AB. The increasing trend in caesarean section rates: global, regional and national estimates: 1990-2014. PLoS One. 2016;11:e0148343.

2. Bragg F, Cromwell DA, Edozien LC. Variation in rates of caesarean section among English NHS trusts after accounting for maternal and clinical risk: cross sectional study. BMJ. 2010;341:c5065.

3. Organization WH. Appropriate technology for birth. Lancet. 1985;2:436-7.

4. UNICEF, WHO, UNFPA, New York: United Nations Children's Fund. 1997:1.

5. Choudhury CR. Caesarean births: the Indian scenario. Population Association of America. 2008:1-8.

6. Robson MS. Classification of caesarean sections. Fetal Matern Med Rev. 2001;12:23-39.

7. Robson MS. Can we reduce the caesarean section rate? Best Pract Res Clin Obstet Gynaecol. 2001;15:179-94.

8. Padmadas SS, Kumar S, Nair SB, Kumari A. "Caesarean section delivery in Kerala, India: evidence from a National Family Health Survey." Social Science and Medicine. 2000;51(4):511-21.

9. Kant A, Mendiratta S. Classification of cesarean section through Robson criteria: an emerging concept to audit the increasing cesarean section rate. Int $\mathbf{J}$ Reprod Contracept Obstet Gynecol. 2018;7:4674-7.

10. Jogia PD, Lodhiya KK. Analysis of caesarean sections according to modified Robson's ten group classification system at a tertiary care centre in Western India. Int J Reprod Contracept Obstet Gynecol. 2019;8:433-9. 
11. Pereira MN, Leal MC, Pereira AP, Domingues RM, Torres JA, Dias MA, et al. Use of Robson classification to assess cesarean section rate in Brazil: the role of source of payment for childbirth. The Author(s) Reproductive Health. 2016;13(Suppl 3): 128 .

12. Kansara V, Patel S, Aanand N, Muchhadia J, Kagathra B, Patel R. A recent way of evaluation of cesarean birth rate by Robson's 10-group system. J Med Pharmaceut Allied Sci. 2014;01:62-70.

13. Dhodapkar SB, Bhairavi S, Daniel M, Chauhan NS, Chauhan RC. Analysis of caesarean sections according to Robson's ten group classification system at a tertiary care teaching hospital in South India. Int J Reprod Contracept Obstet Gynecol. 2015;4:745-9.

14. Shirsath A, Risbud N. Analysis of cesarean section rate according to Robson's 10-group classification system at a tertiary care hospital. Int J Sci Res. 2014;3(1):401-2.

15. Patel RV, Gosalia EV, Vasa PB, Pandya VM. Indications and trends of caesarean birth delivery in the current practice scenario. Int J Reprod Contracept Obstet Gynecol. 2014;3:575-80.

16. Katke RD, Zarariya AN, Desai PV. LSCS audit in a tertiary care center in Mumbai: to study indications and risk factors in LSCS and its effect on early perinatal morbidity and mortality rate. Int J Reprod Contracept Obstet Gynecol. 2014;3:963-8.

17. Abdel-Aleem H, Shaaban OM, Hassanin Al, Ibraheem AA. Analysis of cesarean delivery at Assiut University Hospital using the ten group classification system. Int $\mathbf{J}$ Gynaecol Obstet. 2013;123(2):119-23.

18. Wanjari SA. Rising caesarean section rate: a matter of concern? Int J Reprod Contracept Obstet Gynecol. 2014;3:728-31.

19. Samba A, Mumuni K. A review of caesarean sections sections using the ten-group classification system (Robson classification) in the Korle-Bu Teaching Hospital (KBTH), Accra, Ghana. Gynecol Obstet. 2016;6:385
20. Betrán AP, Gulmezoglu AM, Robson M, Merialdi M, Souza JP, Wojdyla D, et al. WHO global survey on maternal and perinatal health in Latin America: classifying caesarean sections. Reprod Health. 2009;29(6):18.

21. Lafitte AS, Dolley $P$, Le Coutour X. Rate of caesarean sections according to the Robson classification: Analysis in a French perinatal network - Interest and limitations of the French medicoadministrative data (PMSI). J Gynecol Obstet Hum Reprod. 2018;47:39-44.

22. Vogel JP, Betrán AP, Vindevoghel N, Souza JP, Torloni MR, Zhang J, et al., Use of the robson classification to assess caesarean section trends in 21 countries: a secondary analysis of two WHO multicountry surveys. The Lancet Globel Health. 2015;3(5):e260-70.

23. Stavrou EP, Ford JB, Shand AW. Epidemiology and trends for Caesarean section births in New South Wales, Australia: a population-based study. BMC Pregnancy Childbirth. 2011;11(8):2393.

24. Vogel JP, Souza JP, Gülmezoglu AM. Patterns and Outcomes of Induction of Labour in Africa and Asia: a secondary analysis of the WHO Global Survey on Maternal and Neonatal Health. PLoS One. 2013;8:e65612.

25. Brennan DJ, Murphy M, Robson MS, O'Herlihy C. The singleton, cephalic, nulliparous woman after 36 weeks of gestation: contribution to overall cesarean delivery rates. Obstet Gynecol. 2011;117:273-9.

26. Stavrou EP, Ford JB, Shand AW. Epidemiology and trends for caesarean section births in New South Wales, Australia: a population- based study. BMC Pregnancy Childbirth. 2011;11(1):8.

Cite this article as: Shenoy HT, Shenoy ST, Anaswara T, Remash K. Analysis of caesarean delivery using Robson ten group classification system at a tertiary care teaching institute in Kerala, India. Int J Reprod Contracept Obstet Gynecol 2019;8:1990-8. 